\title{
Frequência de ocorrência de carcinoma basocelular palpebral na região Centro-0este paulista e características dos portadores
}

\author{
Frequency of occurrence of eyelid basal cell carcinoma in the centralwest region of \\ São Paulo State and carriers characteristics
}

Silvia Narikawa ${ }^{1}$, Carlos Roberto Padovani ${ }^{2}$, Silvana Artioli Schellini ${ }^{1}$

\section{RESUMO}

Objetivo: Observar a frequência de ocorrência do carcinoma basocelular palpebral na região Centro-Oeste paulista e descrever o perfil demográfico dos portadores.

Métodos: Estudo transversal, de amostragem aleatória, realizado em doze cidades da região Centro-Oeste do Estado de São Paulo. Foram examinados 11.167 indivíduos. Os pacientes foram avaliados em uma Unidade Móvel, com atendimento oftalmológico completo. O diagnóstico de carcinoma basocelular palpebral foi feito através do exame clínico e biomicroscópico da lesão. Os pacientes diagnosticados foram encaminhados ao Ambulatório de Plástica Ocular da Faculdade de Medicina de Botucatu para tratamento. Os dados foram submetidos à análise de frequência de ocorrência. Resultados: Cinco casos de carcinoma basocelular palpebral foram identificados na amostra, correspondendo a uma frequência de ocorrência de 0,045\%. Quatro pacientes eram do sexo feminino, a maioria com idade maior ou igual a 70 anos e todos os casos tinham a cor da pele branca. Apenas três indivíduos encaminhados compareceram ao serviço para exérese da lesão e confirmação diagnóstica.

Conclusão: $\mathrm{O}$ carcinoma basocelular palpebral acomete $0,045 \%$ dos habitantes da região Centro-Oeste paulista, afetando principalmente o sexo feminino, na faixa etária próxima dos 70 anos.

Descritores:Carcinoma basocelular/diagnóstico; Carcinoma basocelular/epidemiologia; Neoplasias palpebrais/epidemiologia; Estudos transversais

\begin{abstract}
Purpose: To observe the frequency of occurrence of eyelid basal cell carcinoma in the centralwest region of São Paulo State and to describe the demographic profile of the basal cell carcinoma carriers.

Methods: Transversal study, using a random sampling, carried out in 12 cities in the centralwest region of São Paulo State evolving 11,167 individuals. Patients were evaluated in a Mobile Unit, with complete ophthalmologic evaluation. The diagnosis of eyelid basal cell carcinoma was done through clinical examination and biomicroscopy of the lesion if desirable. The basalcell carcinoma carriers diagnosed werereferred to Oculoplastic Clinic of Faculdade de Medicina de Botucatu for treatment. Data were submitted to analysis of frequency of occurrence.

Results: Five cases of eyelid basal cell carcinoma wereidentified in the sample, corresponding to a frequency of occurrence of $0.045 \%$. Four patients were female, most with age equalorgreaterthan 70 year-old and all the cases had whiteskin color. Only three individuals conveyed attended the service for excision of the lesion and diagnostic confirmation. Conclusion: The eyelid basal cell carcinoma affects $0.045 \%$ of the inhabitants of the centralwest region of São Paulo State, affecting mainly the 70 year-old female range.
\end{abstract}

Keywords: Carcinoma, basal cell/diagnosis; Carcinoma, basal cell/epidemiology; Eyelid neoplasms/epidemiology; Cross-sectionalstudies

\section{INTRODUÇÃO}

Os tumores palpebrais podem ser malignos ou benignos e são frequentemente observados na prática oftalmológica diária, sendo os tumores benignos os predominantes. Dentre os tumores malignos, o carcinoma basocelular $(C B C)$ é responsável por $75^{(1)}$ a $92 \%{ }^{(2)}$ dos tumores palpebrais malignos, com localização mais frequente na pálpebra inferior, seguida do canto medial( ${ }^{(3-5)}$.

Ocorre geralmente em idosos, estando o maior número de portadores na faixa de 50 a 70 anos, sendo rara a possibilidade de ocorrência antes dos 40 e depois dos 80 anos ${ }^{(6,7)}$.

Clinicamente o CBC pode ser classificado como nodular, nódulo ulcerativo, pigmentado e planocicatricial (ou infiltrativo), sendo o tipo nodular, o mais comum ${ }^{(4)}$.

Caracteristicamente o CBC é um tumor de crescimento lento, raramente produz metástases, podendo a morbidade estar relacionada à invasão local|(5,8,9), com maior risco de extensão orbitária e intracraniana, em especial quando localizado no canto interno ${ }^{(4)}$.
Indivíduos que desenvolvem um CBC possuem maior chance de ter outros tipos de câncer de pele, como o melanoma e o carcinoma espinocelular ${ }^{(10)}$, assim como outros tipos de tumores não cutâneos, em diversos sítios ${ }^{(11)}$.

A taxa de mortalidade devido ao CBC localizado na região ocular é aproximadamente de 3\% e, em geral, decorre de extensão intracraniana dos tumores que não foram tratados adequadamente ou foram negligenciados ${ }^{(4)}$.

O diagnóstico precoce destas lesões reduz a morbidade, a invasão orbitária secundária, assim como as recorrências. Entre os fatores que pioram o prognóstico estão a recorrência prévia, os subtipos histológicos mais agressivos (esclerosante), as lesões mais extensas e a invasão perineural(5).

O Brasil é um país de clima tropical, com sol forte na grande maioria do território e durante a maior parte do ano. A radiação ultravioleta é sabidamente um fator de risco para o desenvolvimento deste tumor. Acresce-se a estes fatores, o fato de aqui viverem muitos descen- 
dentes de europeus que trabalham na lavoura, indivíduos mais predispostos ao desenvolvimento dos tumores. Outros fatores associados à gênese da lesão são história familiar positiva, ingestão deficiente de vitaminas, dieta rica em gordura, entre outros ${ }^{(10)}$

Apesar da existência de todos estes fatores relacionados ao CBC, não há estudos populacionais brasileiros que nos apontem qual é a frequência de ocorrência do CBC no nosso meio.

\section{OBJETIVO}

Observar a frequência de ocorrência do CBC palpebral na região Centro-Oeste paulista e descrever o perfil demográfico dos portadores.

\section{MÉTODOS}

Este é um estudo do tipo transversal, de caráter observacional e de amostragem aleatória, realizado em doze cidades da região Centro-Oeste do Estado de São Paulo, para as quais o centro de referência em Saúde é a cidade de Botucatu.

Os participantes foram determinados por sorteio, baseado nos setores censitários do Censo do IBGE, que levou em conta o local de moradia. Foi sorteada a primeira casa do setor censitário e, a partir dela, e em sequências de cinco, foram escolhidas as demais moradias das quais seriam examinados os habitantes, ou seja, todos os indivíduos que moravam na residência eram considerados elegíveis para o estudo. A amostra a ser examinada foi estabelecida em 11.167 sujeitos. Todos os exames foram realizados utilizando uma Unidade Móvel Oftalmológica, seguindo o protocolo da pesquisa que consistia de dados demográficos e exame oftalmológico completo (anamnese, antecedentes oculares e sistêmicos, antecedentes familiares, avaliação da acuidade visual com e sem correção, tonometria, biomicroscopia, fundoscopia e exame refracional).

O diagnóstico de CBC da pálpebra foi feito com base no exame clínico da lesão e na biomicroscopia, quando se julgou necessário. Todos os pacientes com diagnóstico da lesão foram encaminhados ao ambulatório de Plástica Ocular da Faculdade de Medicina de Botucatu para tratamento.

Os dados obtidos foram cadastrados em tabela Excel e submetidos à análise de frequência de ocorrência.

\section{RESULTADOS}

A distribuição dos indivíduos examinados segundo sexo demonstra que 6.791 indivíduos (61\%) eram do sexo feminino.

Foram detectados 5 casos de CBC palpebral na amostra estudada. Portanto, a frequência de ocorrência do CBC palpebral em habitantes da região Centro-Oeste do Estado de São Paulo foi de 0,045\%.

As características dos casos detectados encontram-se no quadro 1. Quatro pacientes eram do sexo feminino e apenas um, do sexo masculino. A idade, em geral, foi maior ou igual a 70 anos e todos tinham a cor da pele branca.

A figura 1 mostra um dos casos diagnosticados (paciente 5).

Todos os cinco pacientes com diagnóstico de CBC foram encaminhados ao serviço de Plástica Ocular da Faculdade de Medicina de Botucatu para a cirurgia. Porém, apenas três compareceram à consulta agendada, tendo sido submetidos à exérese da lesão, com confirmação do diagnóstico, como mostra o quadro 1.

\section{DISCUSSÃO}

O CBC é uma afecção muito frequente e pode ser subdiagnosticada por ter um curso indolente. O diagnóstico precoce favorece o prognóstico.

Foram diagnosticados na pesquisa realizada cinco casos de $C B C$ nas pálpebras dos habitantes da região Centro-Oeste do Estado de São Paulo. Ressalte-se que este tipo de pesquisa, feito com base populacional, é inédito no território nacional.

Esses pacientes, sem tratamento, poderiam evoluir para casos graves com comprometimento da visão ou até da vida.

A maioria dos casos detectados eram do sexo feminino, diferente dos dados encontrados na literatura ${ }^{(5,9)}$. Talvez esta diferença tenha sido observada devido ao maior número de mulheres examinadas na amostra total deste estudo, apesar de a tendência mais recente apontar as mulheres como tendo risco semelhante de desenvolvimento da lesão, já que desenvolvem tarefas expostas aos mesmos riscos que os homens.

Os dados como cor da pele branca e paciente com idade mais avançada são semelhantes aos da literatura ${ }^{(5,9)}$. Um único paciente era mais jovem e apresentava a lesão na pálpebra superior, tida como localização menos comum. Infelizmente este paciente não compareceu para realização do tratamento e confirmação histológica da lesão.

Esses pacientes foram detectados na comunidade, sem diagnóstico e sem tratamento, o que reforça a importância dos projetos de prevenção na comunidade.

\section{CONCLUSÃO}

O CBC palpebral acomete $0,045 \%$ dos habitantes da região Centro-Oeste paulista, afetando principalmente indivíduos do sexo feminino, na faixa etária próxima dos 70 anos.

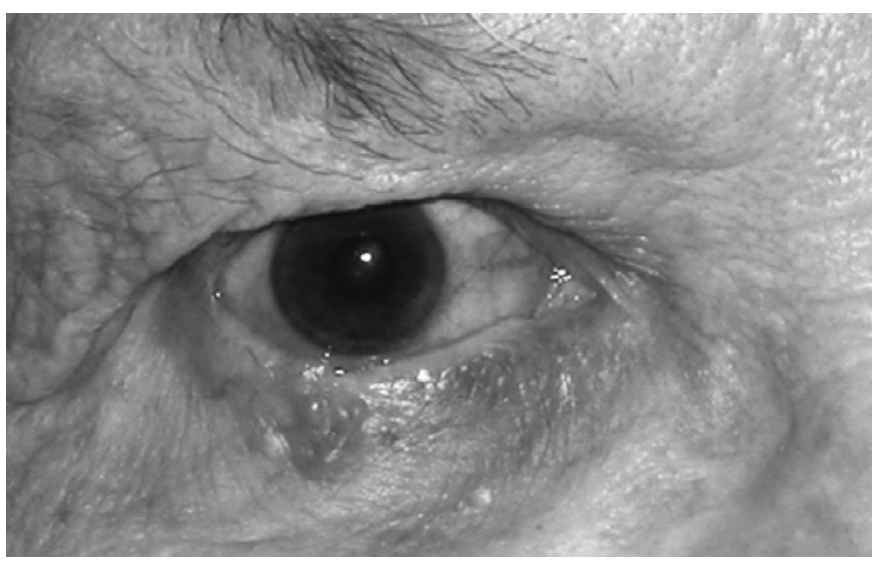

Figura 1.Portador decarcinoma basocelular dotipo nodular, localizadona pálpebra inferior

Quadro 1. Apresentação dos portadores de carcinoma basocelular da pálpebra detectados na população da região Centro-Oeste do Estado de São Paulo - UNESP, 2010

\begin{tabular}{|c|c|c|c|c|c|}
\hline Paciente & Idade & Sexo & Cor da pele & Localização da lesão & Tipo do tumor \\
\hline 1 & 43 & $\mathrm{~F}$ & Branca & Pálpebra superior & Sem informação \\
\hline 2 & 73 & $\mathrm{~F}$ & Branca & Sem informação & Sem informação \\
\hline 3 & 78 & M & Branca & Canto externo & Carcinoma basocelular nodular ulcerado \\
\hline 4 & 77 & $\mathrm{~F}$ & Branca & Sem informação & Carcinoma basocelular sólido infiltrativo \\
\hline 5 & 82 & $\mathrm{~F}$ & Branca & Pálpebra inferior & Carcinoma basocelular sólido ulcerado \\
\hline
\end{tabular}




\section{REFERÊNCIAS}

1. Soares EH, Belo CV, Reis AK, Nunes RR, Mason EM. Tumores malignos da pálpebra. Arq Bras Oftalmol. 2001;64(4):287-9.

2. Schellini SA, Costa JP, Cardilo JA, Paro, PT, Marques ME, Silva MRB. Neoplasias malignas das pálpebras na Faculdade de Medicina de Botucatu. Rev Bras Oftalmol. 1990;49(5):317-23. 3. Deprez M, Uffer S. Clinicopathological features of eyelid skin tumors. A retrospective study of 5540 cases and review of literature. Am J Dermatopathol. 2009;31(3):256-62.

4. Bernardini FP. Management of malignant and benign eyelid lesions. Cur Opin Ophthalmol. 2006;17(5):480-4

5. Soysal HG, Soysal E, Markoç F, Ardiç F. Basal cell carcinoma of the eyelids and periorbita region in a Turkish population. Ophthal Plast Reconstr Surg. 2008;24(3):201-6.
6. Aurora AL, Blodi FC. Lesion of the eyelids: a clinicopathological study. Surv Ophthalmol. 1970;15:94-104

7. Pereira IC, Schellini SA, Silva MR, Marques MEA, Padovani CR. Aspectos do carcinoma basocelular palpebral na região de Botucatu (SP). Rev Bras Oftalmol. 2000; 59(10):737-43.

8. Netscher DT, Spira M. Basal cell carcinoma: An overview of tumor biology and treatment. Plast Reconstr Surg. 2004;113(5):74 e- 94 e.

9. Brooke R. Basal cell carcinoma. Clin Med. 2005:5(6):551-4

10. Wong CS, Strange RC, Lear JT. Basal cell carcinoma. BMJ. 2003;327(7418):794-8.

11. Frisch M, Hjalgrim H, Olsen JH, Melbye M. Risk for subsequent cancer after diagnosis of basal cell carcinoma: a population - based, epidemiologic study. Ann Intern Med. 1996; 125(10):815-21. Comment in: Ann Intern Med. 1997;127(1):87; author reply 87-8. Ann Intern Med. 1996;125(10):852-4. Ann Intern Med. 1997;127(1):87; author reply 87-8.

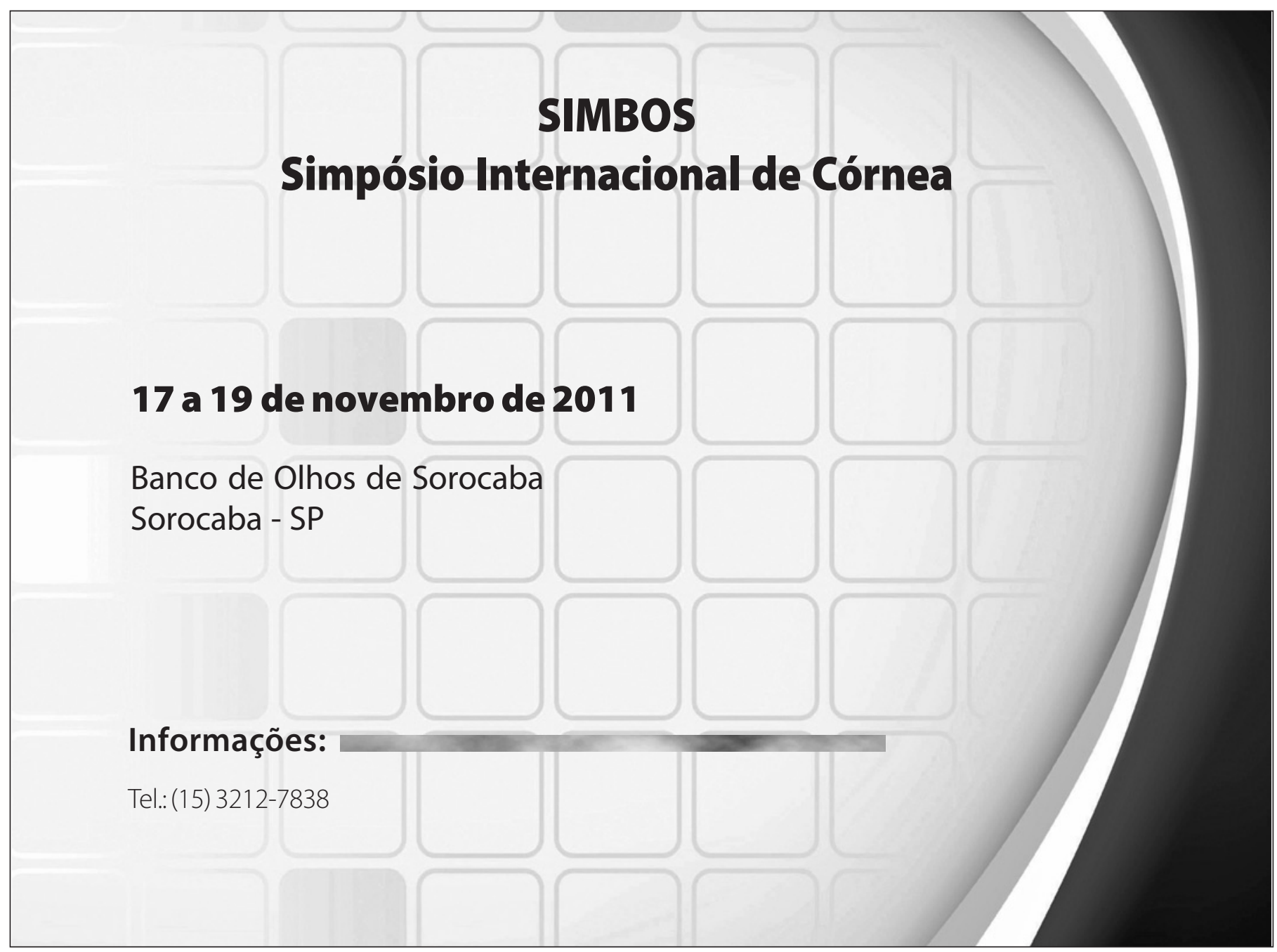

